\title{
Online Searches for Quitting Vaping During the 2019 Outbreak of E-cigarette or Vaping Product Use-Associated Lung Injury
}

\author{
Sara Kalkhoran, MD, MAS ${ }^{1,2}{ }^{\infty}$, Yuchiao Chang, $P h D^{1,2}$, and Nancy A. Rigotti, MD 1,2 \\ ${ }^{1} T o b a c c o$ Research and Treatment Center, Division of General Internal Medicine, Massachusetts General Hospital, Boston, MA, USA; ${ }^{2}$ Harvard \\ Medical School, Boston, MA, USA.
}

$\mathrm{J}$ Gen Intern Med 36(2):559-60

DOI: $10.1007 / \mathrm{s} 11606-020-05686-5$

(c) Society of General Internal Medicine 2020

\section{INTRODUCTION}

The prevalence of current e-cigarette use (vaping) is increasing among both adults and adolescents. ${ }^{1,2}$ Many e-cigarettes, such as JUUL and other pod systems, deliver nicotine to users at a high level that is comparable to cigarette smoking. ${ }^{3}$ Hence, many e-cigarette users, even those who do not also smoke cigarettes, may have developed nicotine dependence from vaping. These individuals might have difficulty if they attempt to stop vaping.

The 2019 outbreak of e-cigarette, or vaping, product useassociated lung injury (EVALI) in the USA, with over 2000 cases and 40 deaths by November, ${ }^{4}$ raised concerns about the health effects of e-cigarette use or vaping and may have increased users' interest in quitting. The outbreak also led to partial or complete bans on sales of e-cigarettes and vaping products in several states. ${ }^{5}$ These may have further stimulated interest in stopping e-cigarette use. There have been no longitudinal studies to date to assess changes in e-cigarette use during this time. The goal of this study was to evaluate trends in internet searches for quitting e-cigarettes/vaping before and during the EVALI outbreak.

\section{METHODS}

We used Google Trends (trends.google.com) to search for terms related to quitting e-cigarettes and vaping ("quit vaping," "quitting vaping," "quitting JUUL," "quit JUULing," and "quit JUUL") from the week of November 4, 2018, to the week of October 27, 2019. We looked at relative search interests, where data are normalized to the time and location of the search and indexed from a scale of 0 to 100 , with 100 being the week with the maximum search interest during the time period we evaluated.

Received January 8, 2020

Accepted January 26, 2020

Published online February 12, 2020
We categorized the one-year data into three periods: before July 25, 2019 (date of the first reported cases of illness in the media), from July 25, 2019, to September 8, 2019 (the week with maximum search interest), and after September 8, 2019. We used an interrupted time series approach to compare the relative search interest in the three periods. All analyses were done using SAS version 9.4 (Cary, NC).

\section{RESULTS}

As shown in Figure 1, the relative search interest in quitting ecigarettes started increasing shortly after July 25,2019 . Compared with the would-be observed volume from the original time trend (dotted line), there was a 3.7-fold increase on September 8, $2019(P<0.001)$. At the end of the evaluation period (week of October 27, 2019), the relative search interest returned to the level predicted by the original trend. The slopes from the increasing trend from July 25, 2019, to September 8, 2019, and the decreasing trend after September 8, 2019, were both significantly different from the trend before July 25, 2019 (both with $P<0.001$ ).] $\rightarrow$

\section{DISCUSSION}

Internet searches for quitting e-cigarette use increased at the time of the outbreak of EVALI in the USA. The fact that individuals seek information about how to quit e-cigarettes suggests that many users are dependent on these products and may need behavioral and/or pharmacologic assistance to quit. Limitations of this analysis are that our list of search terms may not be exhaustive and that we cannot determine whether the individuals searching for information about quitting vaping are users of the products. However, these findings are consistent with a report that most adult e-cigarette users wanted to quit e-cigarettes at some point, and many had already tried to quit even before the EVALI outbreak. ${ }^{6}$ Healthcare providers, particularly those caring for adolescents and young adults, should routinely screen for and document ecigarette use in addition to combustible tobacco use to identify e-cigarette users and assist those who are interested in or trying 


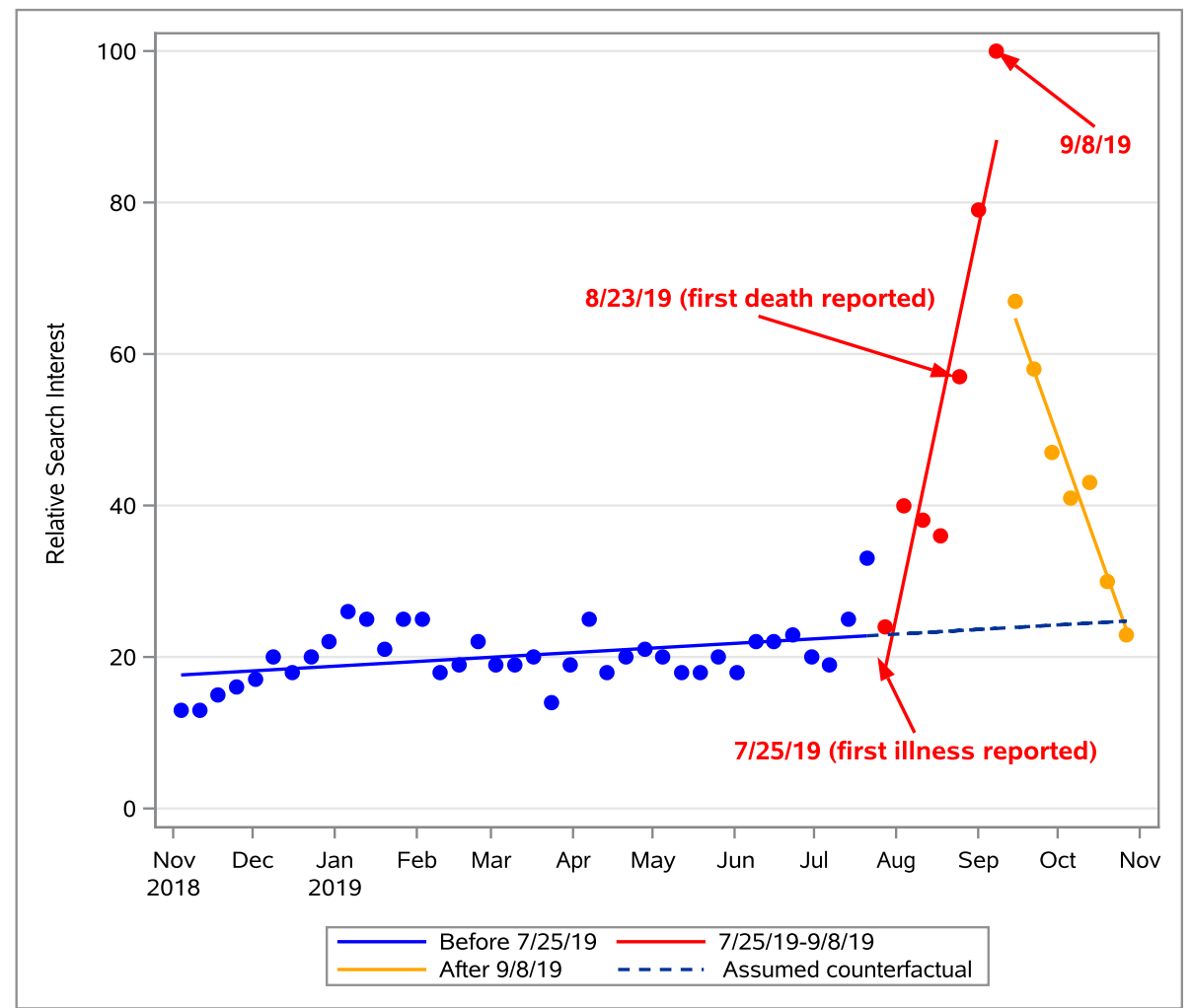

Figure 1 Relative search interest in quitting vaping from the week of 11/4/2018 to the week of 10/27/2019. Relative search interests were obtained from Google Trends, and data are indexed from a scale of 0 to 100 , with 100 being the week with the maximum search interest. The data are divided into 3 time periods: from before 7/25/19 (date of the first reported cases of illness in the media, shown in blue), from 7/25/19 to 9/8/19 (the week with maximum search interest, shown in red), and after 9/8/19 (shown in yellow). The blue dotted line represents the would-be relative search interest from the time trend before $7 / 25 / 2019$.

to quit. Further research is necessary to determine the best ways to help e-cigarette users quit.

Corresponding Author: Sara Kalkhoran, MD, MAS; Tobacco Research and Treatment Center, Division of General Internal Medicine Massachusetts General Hospital, Boston, MA, USA (e-mail: skalkhoran@mgh.harvard.edu).

Funding Information This study was supported by the National Heart, Lung, and Blood Institute (NHLBI) of the National Institutes of Health (K23HL136854 to Dr. Kalkhoran).

\section{Compliance with Ethical Standards:}

Conflict of Interest: Drs. Rigotti and Kalkhoran receive royalties from UpToDate, Inc. Dr. Kalkhoran has a family financial interest in Google, Inc. Dr. Rigotti has been an unpaid consultant to Pfizer, Inc. and a paid consultant to Achieve Life Sciences. Dr. Chang has no conflicts of interest to disclose.

Disclaimer: The funders had no role in the design and conduct of the study; collection, management, analysis, and interpretation of the data; preparation, review, or approval of the manuscript; and decision to submit the manuscript for publication.

\section{REFERENCES}

1. Creamer MR, Wang TW, Babb S, et al. Tobacco Product Use and Cessation Indicators Among Adults - United States, 2018. MMWR Morb Mortal Wkly Rep 2019;68:1013-1019. https://doi.org/10.15585/mmwr. mm6845a2

2. Miech R, Johnston L, O'Malley PM, Bachman JG, Patrick ME. Adolescent Vaping and Nicotine Use in 2017-2018 - U.S. National Estimates. N Engl J Med. 2018;380(2):192-3. https://doi.org/10.1056/ NEJMc1814130.

3. Goniewicz ML, Boykan R, Messina CR, Eliscu A, Tolentino J. High exposure to nicotine among adolescents who use Juul and other vape pod systems ('pods'). Tob Control. 2019;28(6):676-7. https://doi.org/10.1136/ tobaccocontrol-2018-054565.

4. Centers for Disease Control and Prevention. Outbreak of Lung Injury Associated with the Use of E-Cigarette, or Vaping, Products 2019. November 13, 2019. https://www.cdc.gov/tobacco/basic_information/ecigarettes/severe-lung-disease.html\#latest-outbreak-information. Accessed November 18, 2019.

5. Corum, J. Vaping Illness Tracker. November 15, 2019. https://www. nytimes.com/interactive/2019/health/vaping-illness-tracker.html. Accessed November 18, 2019.

6. Rosen RL, Steinberg ML. Interest in Quitting E-Cigarettes among Adults in the United States. Nicotine Tob Res. 2019. https://doi.org/10.1093/ ntr/ntz062.

Publisher's Note Springer Nature remains neutral with regard to jurisdictional claims in published maps and institutional affiliations. 